\title{
Capacidade de combinação em genótipos de trigo estimada por meio de análise multivariada
}

\author{
Giovani Benin(1), Giovani Olegário da Silva( ${ }^{(2)}$, Eduardo Stefani Pagliosa(1), Cristiano Lemes ${ }^{(1)}$, \\ Anderson Signorini( ${ }^{(1)}$, Eduardo Beche ${ }^{(1)}$ e Marcio Andrei Capelin ${ }^{(1)}$
}

\begin{abstract}
(1)Universidade Tecnológica Federal do Paraná, Campus Pato Branco, Via do Conhecimento, Km 01, CEP $85501-970$ Pato Branco, PR. E-mail: benin@utfpr.edu.br, eduardopagliosa@yahoo.com.br, cristianolemes.utfpr@gmail.com.br, andersig@yahoo.com.br, eduardo_beche@hotmail.com, macapelin@hotmail.com (2)Embrapa Hortaliças, Rodovia BR 060, Km 09, Caixa Postal 218, CEP 70359-970 Gama, DF. E-mail: olegario@cnph.embrapa.br
\end{abstract}

Resumo - O objetivo deste trabalho foi estimar capacidades de combinação de genótipos de trigo por meio de análise multivariada, de modo a identificar cruzamentos com desempenho superior. Foram cruzados oito genitores de trigo, na forma de dialelo completo, sem os recíprocos. Os cruzamentos e o avanço de geração foram realizados em 2007 no esquema de semeadura em linha cheia, e os híbridos foram avaliados em 2008, em delineamento de blocos casualizados, com três repetições. Os dados foram submetidos a análise de variância uni e multivariada, análise de componentes principais e análise dialélica parcial e multivariada. Os genitores de melhor desempenho para capacidade geral de combinação para os caracteres do grupo 1 (rendimento de grãos, massa de mil grãos, massa de espiga e número de grãos por espiga) e do grupo 2 (dias da emergência à floração, dias da floração à maturação e estatura de planta) foram as cultivares BRS Guamirim e Fundacep Raízes, respectivamente. Os cruzamentos 'BRS Guamirim' x 'Fundacep Cristalino' (para os caracteres do grupo 1) e 'Abalone' x 'Fundacep Cristalino' e 'Abalone' x 'Fundacep Raízes' (para os caracteres do grupo 2) destacam-se pela capacidade específica de combinação.

Termos para indexação: Triticum aestivum, análise dialélica, componentes principais, seleção de genitores.

\section{Combining ability of wheat genotypes estimated by multivariate analysis}

\begin{abstract}
The objective of this work was to estimate the combining ability of wheat lines using multivariate analysis, in order to identify crossing combinations with superior performance. Eight wheat parental lines were crossed in a complete diallel design without reciprocals. Crosses and advanced generations were obtained in the year 2007 in a full-line sowing system, and the hybrids were evaluated in 2008, in a randomized block design with three replicates. The data were treated using univariate and multivariate analysis of variance, principal component analysis, and partial and multivariate diallel analyses. The cultivar BRS Guamirim was the parental genotype with the best performance for general combining ability for group 1 traits (grain yield, thousand grains weight, spike weight and number of grains per spike), whereas the cultivar Fundacep Raízes was the best for group 2 traits (days from emergence to bloom, days from bloom to maturation, and plant height). 'BRS Guamirim' x 'Fundacep Cristalino' (for group 1 traits) and 'Abalone' x 'Fundacep Cristalino' and 'Abalone' x 'Fundacep Raízes' (for group 2 traits) were the best crossings for specific combining ability.
\end{abstract}

Index terms: Triticum aestivum, diallel analysis, principal components, genitor selection.

\section{Introdução}

$\mathrm{Na}$ escolha de genitores de trigo, os melhores cruzamentos são os que apresentam maior probabilidade de fornecer progênies com desempenho superior, com elevado rendimento de grãos e demais caracteres agronômicos e adaptativos importantes para a cultura.

O grande desafio é justamente reunir em um só genótipo a maior frequência possível de alelos favoráveis oriundos das diferentes fontes. Na condução de um programa dessa natureza, questiona-se qual é a estratégia para se obter uma população segregante que possibilite maior sucesso na seleção. Conhecimentos que venham contribuir para o aperfeiçoamento desses processos de escolha são fundamentais.

$\mathrm{Na}$ tentativa de prever o desempenho da progênie de um cruzamento, várias técnicas têm sido propostas para elevar a probabilidade de obtenção de populações segregantes promissoras. Entre elas, podem ser destacadas: a heterose na geração $\mathrm{F}_{1}$ (Lorencetti et al., 2006), a média dos genitores (Antunes et al., 1998), a distância genética entre genitores (Vieira 
et. al., 2007; Benin et al., 2008; Bertan et al., 2009) e a análise dialélica, que determina o potencial dos genitores em combinações híbridas e pode fornecer também informações sobre a ação gênica que controla os caracteres, a herança dos caracteres e a existência de heterose.

A maioria das técnicas biométricas aplicadas a cruzamentos dialélicos são univariadas, e as análises combinadas praticamente restringem-se a procedimentos bivariados. A análise dos caracteres feita isoladamente pode não ser suficiente, pois não considera as correlações existentes entre eles (Jung et al., 2007), de forma que a seleção baseada em um determinado caractere pode ocasionar alterações em outros, que podem ou não ser de interesse para o melhoramento. O método de Griffing (1956) tem sido o mais empregado para análise e interpretação de cruzamentos dialélicos (Pfann et al., 2009). Esse método possibilita estimar os efeitos e as somas de quadrados de efeitos da capacidade geral de combinação (CGC), dependente da concentração de genes predominantemente aditivos, e da capacidade específica de combinação (CEC), que é resultante da concentração de genes de efeito não aditivo. Em tal metodologia, as diversas variáveis mensuradas são analisadas isoladamente, o que gera dificuldades no melhoramento genético do trigo, pois diversos caracteres precisam ser melhorados simultaneamente.

Uma alternativa é a utilização da análise dialélica multivariada, que permite combinar múltiplas informações obtidas na unidade experimental, facilita a seleção e possibilita a discriminação das populações mais promissoras (Sakaguti, 1994; Yan \& Hunt, 2002; Ledo et al., 2003; Jung et al., 2007; Silva et al., 2008). Para a utilização da informação da análise de variância multivariada, pode-se utilizar uma ampla gama de metodologias multivariadas para complementar os resultados obtidos e propiciar subsídios para utilização prática das informações resultantes. Dentre as várias possibilidades, destacam-se as variáveis canônicas, os componentes principais, a análise de fatores e os índices de seleção (Ledo et al., 2003; Cruz, 2006).

Este trabalho foi realizado com o objetivo de determinar as capacidades gerais e específicas de combinação para dois grupos de caracteres por meio de cruzamento dialélico e do uso de análise multivariada, a fim de obter informações genéticas úteis para a seleção de genitores em trigo para panificação.

\section{Material e Métodos}

$\mathrm{Na}$ safra agrícola de 2006, foram realizados cruzamentos artificiais entre oito cultivares de trigo (BRS Guamirim, BRS Timbaúva, BRS 208, Abalone, CD 111, CD 113, Fundacep Cristalino, Fundacep Raízes), com base no modelo dialélico completo, sem os recíprocos. Tais genitores foram escolhidos por terem sido recentemente disponibilizados para cultivo, apresentarem elevado potencial produtivo e serem contrastantes para diversos caracteres agronômicos.

A geração F2 foi obtida pela autofecundação de plantas F1, na estação fria da safra agrícola de 2007. $\mathrm{O}$ experimento, que contemplou as 28 populações F2 e seus genitores, foi implantado no dia 5 de julho de 2008, na área experimental do curso de Agronomia da Universidade Tecnológica Federal do Paraná, Campus Pato Branco $\left(26^{\circ} \mathrm{S}, 52^{\circ} \mathrm{W}\right.$, com altitude média de $700 \mathrm{~m}$ ), localizado na zona tritícola F. O solo dessa área é classificado como Latossolo Vermelho distrófico, com textura argilosa.

Foi utilizado o delineamento de blocos ao acaso, com três repetições e as parcelas compostas por cinco linhas de $4 \mathrm{~m}$ de comprimento e espaçamento de 0,20 m entre linhas, com densidade de semeadura de 350 sementes $\mathrm{m}^{-2}$. A adubação de base foi de $300 \mathrm{~kg} \mathrm{ha}^{-1}$ de NPK (5-20-20) e mais $60 \mathrm{~kg} \mathrm{ha}^{-1}$ de nitrogênio aplicado no início do afilhamento. O controle de plantas invasoras foi realizado mediante capina manual.

Foram avaliados os seguintes caracteres: rendimento de grãos, em gramas, determinado pela colheita e trilha de todas as plantas da parcela, transformado em $\mathrm{kg} \mathrm{ha} \mathrm{ha}^{-1}(\mathrm{RG})$; estatura de planta no início da maturação fisiológica (EP), aferida em centímetros, da base das plantas (nível do solo) até o ápice das espigas, excluídas as aristas; dias da emergência à floração (DEF), tendo como referência o florescimento de mais de $50 \%$ das espigas; dias da floração à maturação fisiológica (DFM); massa de mil grãos (PMG), em gramas, estimada a partir da massa de 200 grãos; massa de espiga (PE), em gramas, determinada em 15 espigas colhidas de forma aleatória na parcela; número de grãos por espiga (NGE), considerado o número médio de grãos contados em 15 espigas, colhidas ao acaso em cada parcela.

Para a análise dos dados, os caracteres avaliados foram divididos em dois grupos. No primeiro grupo, foram reunidos o rendimento de grãos e seus componentes - massa de mil grãos, massa de espiga e 
número de grãos por espiga - e, no segundo grupo, os caracteres adaptativos - dias da emergência à floração, dias da floração à maturação e estatura de planta.

Os dados foram submetidos à análise de homogeneidade de variância (teste de Bartllet) e de normalidade (Lilliefors) (Cruz, 2006). As análises dialélicas foram efetuadas de forma univariada, considerando a metodologia de dialelos completos com inclusão das combinações P2, de acordo com a metodologia de Griffing (1956), com estimação dos efeitos da capacidade geral de combinação (CGC) e da capacidade específica de combinação (CEC).

As análises por componentes principais foram realizadas com uso da metodologia descrita por Cruz \& Regazzi (1997). Após a determinação do número de componentes principais, que envolveram um mínimo de $80 \%$ da variação disponível, foram estimados os escores para cada componente principal e sua importância relativa.

Em seguida, foi realizada análise dialélica dos escores dos componentes, com obtenção também dos efeitos das capacidades combinatórias, geral e específica, para cada componente, de acordo com a metodologia descrita por Ledo et al. (2003). A hipótese de igualdade dos efeitos genéticos da análise dialélica multivariada foi avaliada com o teste de Wilks, com uso da aproximação F (Harris, 1975). Os caracteres mais importantes na determinação do primeiro e do segundo componente principal foram identificados por meio da correlação entre os componentes principais e a média dos caracteres, por meio do programa SAS (SAS Institute, 2002).

\section{Resultados e Discussão}

A análise de variância univariada apontou efeito significativo dos tratamentos em todos os caracteres dos grupos 1 e 2 (Tabela 1), o que indica que os genitores e suas respectivas combinações híbridas são contrastantes. Da mesma forma, a análise da variância da extensão multivariada do modelo de Griffing (1956) revelou efeitos significativos da capacidade específica de combinação e da capacidade geral de combinação sobre os caracteres do grupo 1 (RG, PMG, PE e NGE) e do grupo 2 (DEF, DFM e EP) (Tabela 2), o que indica que os genitores apresentam genes complementares e que os caracteres podem ser considerados conjuntamente na análise dialélica (Ledo et al., 2003; Silva et al., 2008). A subdivisão dos caracteres em grupos foi importante, pois reuniu, no primeiro grupo, caracteres que precisam ter sua expressão maximizada (associação positiva e de elevada magnitude com os componentes principais), e, no segundo grupo, os caracteres adaptativos do ciclo vegetativo (DEF) e reprodutivo (DFM) e a estatura de plantas, cuja redução da expressão é importante para o setor produtivo (associação negativa e de elevada magnitude com os componentes principais). Isso evitou que associações positivas e negativas confundissem os resultados.

A importância da existência de diferenças (variabilidade) na expressão dos caracteres pelos genitores para a capacidade de combinação em trigo foi verificada por Bertan et al. (2009), que avaliaram sete caracteres agronômicos nas gerações F1 e F2 de 15 híbridos, semeados de acordo com dois métodos de semeadura, e detectaram que a presença de variabilidade

Tabela 1. Quadrados médios da análise de variância univariada e correlação de Pearson entre os caracteres e os dois primeiros componentes principais (CP1 e CP2), para sete caracteres agronômicos de trigo avaliados em genitores e suas combinações híbridas em um delineamento dialélico.

\begin{tabular}{|c|c|c|c|c|c|c|c|c|}
\hline \multirow[t]{2}{*}{ Fonte de variação } & \multirow[t]{2}{*}{ GL } & \multicolumn{7}{|c|}{ Caracteres $^{(1)}$} \\
\hline & & $\mathrm{RG}$ & PMG & PE & NGE & $\mathrm{DEF}$ & DFM & $\mathrm{EP}$ \\
\hline Blocos & 2 & $93.421,9$ & 1,03 & 0,09 & 129,8 & 0,25 & 0,45 & 1,50 \\
\hline Tratamentos ${ }^{(2)}$ & 35 & $585.681,8 * *$ & $8,60 * *$ & $0,11 *$ & $76,4 * *$ & $29,90 * *$ & $53,50 * *$ & $122,90 * *$ \\
\hline Resíduo & 70 & $42.411,5$ & 4,13 & 0,05 & 34,2 & 1,58 & 2,59 & 5,50 \\
\hline \multirow[t]{2}{*}{$\mathrm{CV}$} & - & 10,8 & 7,13 & 14,14 & 16,3 & 1,66 & 1,29 & 2,92 \\
\hline & & \multicolumn{7}{|c|}{ Correlação de Pearson } \\
\hline CP1 & - & $-0,03^{\mathrm{ns}}$ & $0,41 *$ & $0,94 * *$ & $0,90 * *$ & $0,75^{* *}$ & $0,77 * *$ & $-0,61 * *$ \\
\hline $\mathrm{CP} 2$ & - & $0,85^{* *}$ & $0,73 * *$ & $-0,06^{\mathrm{ns}}$ & $-0,22^{\mathrm{ns}}$ & $0,37 *$ & $0,25^{\mathrm{ns}}$ & $0,78^{* *}$ \\
\hline
\end{tabular}

${ }^{(1)} \mathrm{RG}$, rendimento de grãos; PMG, massa de mil grãos; PE, massa de espiga; NGE, número de grãos por espiga; DEF, dias da emergência à floração; DFM, dias da floração à maturação; EP, estatura de planta. ${ }^{(2)}$ Genitores 'BRS Guamirim', 'BRS Timbaúva', 'BRS 208', 'Abalone', 'CD 111', 'CD 113', 'Fundacep Cristalino', 'Fundacep Raízes'. ns Não significativo. * e **significativo a 1 e $5 \%$ de probabilidade, respectivamente. GL, graus de liberdade; CV, coeficiente de variação. 
para os caracteres nos genitores foi determinante para as capacidades de combinação significativas.

Com apenas dois componentes principais, foi possível reunir de 79,83 a $80,57 \%$ da variação total disponível entre as médias de cruzamentos do dialelo, para os grupos de caracteres 1 e 2. De acordo com Cruz (2006), para uma interpretação satisfatória da variabilidade manifestada entre genótipos, é necessário que os dois primeiros componentes principais permitam estimativas mínimas de $80 \%$ da variação total contida no conjunto de caracteres analisados.

É possível observar que, para o primeiro grupo de caracteres (RG, PMG, PE e NGE), o componente principal 1 (CP1) apresentou associação positiva de elevada magnitude com a massa da espiga $(0,94)$ e o número de grãos por espiga $(0,90)$. Essa análise serve para indicar quais caracteres estão mais relacionados a cada componente principal (Ledo et al., 2003), e possibilita inferências acerca da magnitude e da direção da associação. Assim, para esse grupo de caracteres, são altamente desejáveis associações positivas e de elevada magnitude com os componentes principais, pois, ao tratar do rendimento de grãos e seus componentes, busca-se maximizar seu desempenho. Neste caso, se o objetivo for a melhoria simultânea da massa da espiga e do número de grãos por espiga, os cruzamentos de melhor capacidade específica de combinação (Tabela 3 ) deverão ser escolhidos em relação ao CP1. Entretanto, se o objetivo for a obtenção de populações segregantes superiores para rendimento de grãos e massa média de grãos, a escolha das melhores combinações híbridas deverá ser feita em relação à capacidade específica de combinação do CP2, já que ele foi positivamente associado com rendimento de grãos $(0,85)$ e massa média de grãos $(0,73)$ (Tabela 1$)$.

A grande maioria dos programas de melhoramento de trigo tem por objetivo selecionar cultivares de menor estatura, que possibilitem maior investimento em adubação nitrogenada sem que haja risco de acamamento, e mais precoces, para melhor se inserirem em esquemas de sucessão de culturas e estarem expostas a fatores bióticos e abióticos por um menor período de tempo. Nesse sentido, para os caracteres do grupo 2, observa-se que o caráter estatura da planta foi negativamente associado ao CP1 $(-0,61)$. Entretanto, os caracteres dias da emergência à floração e dias da floração à maturação foram positivamente associados com o CP1 $(0,75$ e 0,77 , respectivamente), o que indica que, para o conjunto de combinações híbridas estudadas, há poucas chances de obtenção de progresso genético na seleção de plantas que combinem baixa estatura e precocidade. Dessa forma, a maior probabilidade de obtenção de progênies mais precoces será obtida pela escolha dos menores valores (mais negativos) das capacidades de combinação para o CP1, pois o objetivo é a diminuição na magnitude dos caracteres; porém, provavelmente não seriam conseguidos progressos na diminuição da estatura das plantas. Outra estratégia seria a escolha das capacidades de combinação com valores mais negativos no $\mathrm{CP} 2$, no qual, apesar de a correlação com os caracteres de precocidade não ser tão alta, é possível associar a seleção para menor ciclo e menor estatura.

A magnitude da capacidade geral de combinação (CGC) é dependente da variância genética aditiva e epistática aditiva $\mathrm{x}$ aditiva, sendo que estimativas

Tabela 2. Resumo de análise de variância multivariada de sete caracteres agronômicos e adaptativos de genótipos de trigo, capacidade geral de combinação (CGC) e capacidade específica de combinação (CEC), analisados em dois grupos, segundo o modelo IV de Griffing (1956).

\begin{tabular}{|c|c|c|c|c|c|c|c|}
\hline Fonte de variação & GL & Matriz de SQP & $\Lambda$ & $\mathrm{F}$ & v1 & $\mathrm{v} 2$ & $p$ \\
\hline & & \multicolumn{6}{|c|}{ Caracteres do grupo $1^{(1)}$} \\
\hline CGC & 7 & $\mathrm{SQP}$ (CGC) & 0,000 & 500,09 & 28 & 243 & 0,000 \\
\hline $\mathrm{CEC}$ & 28 & SQP (CEC) & 0,000 & 213,49 & 112 & 269 & 0,000 \\
\hline \multirow[t]{2}{*}{ Resíduo } & 70 & SQP (Resíduo) & & & & & \\
\hline & & \multicolumn{6}{|c|}{ Caracteres do grupo $2^{(2)}$} \\
\hline CGC & 7 & SQP (CGC) & 0,000 & $1.721,37$ & 21 & 195,80 & 0,000 \\
\hline $\mathrm{CEC}$ & 28 & SQP (CEC) & 0,000 & 998,60 & 84 & 204,30 & 0,000 \\
\hline Resíduo & 70 & SQP (Resíduo) & & & & & \\
\hline
\end{tabular}

${ }^{(1)} \mathrm{RG}$, rendimento de grãos; PMG, massa de mil grãos; PE, massa de espiga e NGE, número de grãos por espiga. ${ }^{(2)} \mathrm{DEF}$, dias da emergência à floração; DFM, dias da floração à maturação; EP, estatura de planta. GL, graus de liberdade; $\Lambda$, estimativa do valor de Wilks. 
muito baixas indicam que a CGC, com base em seus cruzamentos, não difere da média geral do dialelo. Por outro lado, valores elevados de CGC, positivos ou negativos, indicam que um determinado genitor é muito superior ou inferior aos demais genitores do dialelo (Cruz \& Regazzi, 1997). Para o primeiro grupo de caracteres, é possível observar que a cultivar BRS Guamirim apresentou CGC de 0,61 e 0,68 para CP1 e CP2, respectivamente (Tabela 3). Comportamento semelhante foi observado para 'BRS Timbaúva', que apresentou valores positivos de CGC, mas de menores magnitudes. Esses resultados indicam que a inclusão desses genitores em blocos e cruzamentos é altamente desejável, pois possibilitaria maximizar a expressão do rendimento de grãos, a massa média de grãos, a massa da espiga e o número de grãos por espiga, nas combinações híbridas que estiveram presentes, hipótese embasada na complementaridade de genes (Gandin, 1982). Ao contrário, 'Fundacep Raízes' e 'Fundacep Cristalino', por exemplo, apresentaram valores de CGC negativos e de elevada magnitude para CP1 $(-0,62)$ e CP2 (-0,56), o que demonstra que tais genitores, na média dos cruzamentos, diminuíram a expressão dos caracteres do grupo 1. Ainda na Tabela 3, para o

Tabela 3. Capacidade geral e específica de combinação de genótipos de trigo para dois grupos de caracteres ${ }^{(1)}$ e os dois primeiros componentes principais (CP1 e CP2).

\begin{tabular}{|c|c|c|c|c|}
\hline \multirow[t]{2}{*}{ Genótipos e combinações híbridas } & \multicolumn{2}{|c|}{ Caracteres do grupo 1} & \multicolumn{2}{|c|}{ Caracteres do grupo 2} \\
\hline & $\mathrm{CP} 1$ & $\mathrm{CP} 2$ & CP1 & $\mathrm{CP} 2$ \\
\hline & \multicolumn{4}{|c|}{ Capacidade geral de combinação } \\
\hline BRS Guamirim & 0,61 & 0,68 & 0,48 & $-0,32$ \\
\hline BRS Timbaúva & 0,36 & 0,36 & 0,11 & 0,24 \\
\hline BRS 208 & 0,17 & 0,04 & $-0,31$ & 0,14 \\
\hline Abalone & 0,26 & $-0,32$ & $-0,28$ & $-0,03$ \\
\hline CD 111 & $-0,33$ & 0,11 & $-0,14$ & 0,27 \\
\hline CD 113 & $-0,48$ & $-0,44$ & 0,28 & $-0,05$ \\
\hline Fundacep Cristalino & 0,01 & $-0,56$ & 0,44 & 0,12 \\
\hline \multirow[t]{2}{*}{ Fundacep Raízes } & $-0,62$ & 0,14 & $-0,58$ & $-0,36$ \\
\hline & \multicolumn{4}{|c|}{ Capacidade específica de combinação } \\
\hline BRS Guamirim x BRS Timbaúva & $-1,00$ & $-0,49$ & $-0,54$ & 0,65 \\
\hline BRS Guamirim x BRS 208 & $-0,41$ & 0,11 & $-0,18$ & 0,49 \\
\hline BRS Guamirim x Abalone & 2,01 & $-2,05$ & 1,57 & $-1,44$ \\
\hline BRS Guamirim x CD 111 & $-0,41$ & 0,46 & 0,09 & $-1,62$ \\
\hline BRS Guamirim x CD 113 & $-0,36$ & $-0,07$ & 0,92 & 0,04 \\
\hline BRS Guamirim x Fundacep Cristalino & 1,07 & 2,17 & $-0,20$ & 0,96 \\
\hline BRS Guamirim x Fundacep Raízes & 0,45 & 0,01 & $-1,46$ & 0,00 \\
\hline BRS Timbaúva x BRS 208 & $-1,59$ & 0,05 & $-0,78$ & $-1,11$ \\
\hline BRS Timbaúva x Abalone & $-0,45$ & 0,94 & 0,22 & 0,24 \\
\hline BRS Timbaúva x CD 111 & 2,93 & $-1,68$ & 2,35 & 1,67 \\
\hline BRS Timbaúva x CD 113 & 1,22 & 0,20 & $-1,64$ & 0,40 \\
\hline BRS Timbaúva x Fundacep Cristalino & $-0,26$ & $-0,89$ & 1,53 & $-0,39$ \\
\hline BRS Timbaúva x Fundacep Raízes & $-0,03$ & $-0,28$ & 0,76 & 0,43 \\
\hline BRS $208 \times$ Abalone & $-2,54$ & 0,89 & 1,61 & 0,00 \\
\hline BRS 208 x CD 111 & 0,18 & 0,16 & 0,22 & 0,52 \\
\hline BRS $208 \times$ CD 113 & 1,15 & $-0,46$ & $-1,71$ & $-0,97$ \\
\hline BRS $208 \times$ Fundacep Cristalino & 1,12 & 0,06 & $-1,24$ & 0,62 \\
\hline BRS 208 x Fundacep Raízes & $-0,19$ & $-0,73$ & $-1,19$ & $-0,24$ \\
\hline Abalone x CD 111 & $-1,87$ & $-1,36$ & $-0,50$ & $-0,91$ \\
\hline Abalone x CD 113 & $-0,84$ & 0,52 & 0,97 & $-0,66$ \\
\hline Abalone $\mathrm{x}$ Fundacep Cristalino & 0,86 & 0,89 & $-1,96$ & 0,19 \\
\hline Abalone x Fundacep Raízes & 1,95 & 1,69 & $-0,56$ & 0,51 \\
\hline CD $111 \times$ CD 113 & $-0,14$ & 0,08 & 0,22 & 1,33 \\
\hline CD 111 x Fundacep Cristalino & $-0,55$ & 0,25 & 1,86 & $-0,43$ \\
\hline CD 111 x Fundacep Raízes & 0,95 & $-0,54$ & $-0,69$ & 0,41 \\
\hline CD $113 \times$ Fundacep Cristalino & $-1,02$ & $-0,52$ & $-0,09$ & $-0,80$ \\
\hline CD 113 x Fundacep Raízes & $-0,39$ & $-2,02$ & 0,27 & $-0,39$ \\
\hline Fundacep Cristalino x Fundacep Raízes & $-2,17$ & 1,30 & 0,48 & $-0,32$ \\
\hline
\end{tabular}


segundo grupo de caracteres, o melhor genitor para ciclo precoce foi 'Fundacep Raízes', que apresentou CGC de -0,58 para o CP1. 'Fundacep Raízes' também se destacou na obtenção de progênies superiores para o conjunto de caracteres do grupo 2, e apresentou CGC de -0,36 no CP2. Da mesma forma, 'BRS Guamirim' demonstrou ser um bom genitor para a diminuição da estatura de planta, com CGC de $-0,32$ para o CP2. Ou seja, 'BRS Guamirim' demonstrou CGC desejável para caracteres de ambos os grupos, exceto para caracteres de precocidade, para os quais o melhor genitor seria 'Fundacep Raízes'.

As capacidades específicas de combinação (CEC), observadas na Tabela3, mostrama importância dos efeitos gênicos não aditivos, o que caracteriza a complementação entre os genitores em relação às frequências dos alelos nos locos com alguma dominância. Valores de CEC próximos de zero indicam que as combinações híbridas envolvendo os genitores comportam-se, conforme o esperado na capacidade geral de combinação de seus genitores (Cruz \& Regazzi, 1997). Os altos valores, positivos ou negativos, indicam que o desempenho da combinação híbrida é relativamente superior ou inferior ao esperado, com base na CGC.

No entanto, a simples significância da CEC não é suficiente para recomendar um cruzamento, pois, conforme Paini et al. (1996), a preferência deve recairem combinações híbridas que tenham elevadas estimativas de CEC e que envolvam pelo menos um genitor com maior CGC, pois o efeito aditivo dos alelos favoráveis, relacionado com a CGC, possibilitará maior facilidade na seleção de populações segregantes. Isso reforça a utilização das combinações híbridas que envolvam os genitores 'BRS Guamirim' e 'BRS Timbaúva' para os caracteres do grupo 1 e 'Fundacep Raízes' para os caracteres do grupo 2.

Para os caracteres do grupo 1 (Tabela 3), merece destaque o cruzamento 'BRS Guamirim' x 'Fundacep Cristalino', com CEC positivas e de elevada magnitude para CP1 $(1,07)$ e CP2 $(2,17)$, o que indica grandes possibilidades de obtenção de progênies superiores para o rendimento de grãos e seus componentes, além de 'BRS Guamirim' ter alto valor de CGC. O mesmo pode ser observado para o cruzamento 'Abalone' x 'Fundacep Raízes', no qual a CEC de -0,56 do CP1, do segundo grupo de caracteres, também indica ser possível complementar a seleção com a identificação de plantas de menor estatura. Além disso, a existência de capacidade geral de combinação de alta magnitude para 'Fundacep Raízes' torna possível a recomendação dessa combinação. Por outro lado, a CEC de 'BRS Guamirim' x 'Abalone' (CP1 $=2,01$ e CP2 $=-2,05$ ) indica possibilidade de ganho com a seleção apenas para a massa de espigas e o número de grãos por espiga, devido à elevada magnitude e ao sinal negativo da CEC para CP2, além de esta combinação também ser promissora para menor estatura de plantas $(\mathrm{CP} 2=-1,44$, no grupo 2).

Especificamente para os caracteres do grupo 2, a melhor combinação para favorecerum ciclo mais precoce seria 'Abalone' x 'Fundacep Cristalino' (CP1 = -1,96). Já para menor estatura, seria 'BRS Guamirim' $\mathrm{x}$ 'CD 111' (CP2 = -1,62), ambas com pelo menos um dos genitores com CGC altamente negativas.

Dessa forma, constata-se que a análise de CGC e CEC multivariada com subdivisão de grupos de caracteres possibilita uma informação mais detalhada para a identificação das melhores combinações híbridas. Também possibilita decidir, para as gerações seguintes, quais combinações apresentarão maiores chances de progresso genético para a seleção simultânea ou se apenas alguns caracteres deverão ser priorizados.

\section{Conclusões}

1. A utilização da análise dialélica multivariada para grupos de caracteres é útil na escolha das melhores combinações de genitores.

2. Os genitores que melhor combinaram com os demais, de acordo com a capacidade geral de combinação, foram 'BRS Guamirim' e 'BRS Timbaúva' para os caracteres de rendimento, e 'Fundacep Raízes' para os caracteres indicativos de precocidade e menor estatura.

3. A combinação 'BRS Guamirim' x 'Fundacep Cristalino' é a melhor para os caracteres de rendimento de grãos, massa média de grãos, massa de espiga e número de grãos por espiga.

4. O cruzamento 'BRS Guamirim' $x$ 'Abalone' possibilita ganhos desejáveis para maiores massas de espiga e número de grãos por espiga, além de menor estatura da planta, e o cruzamento 'Abalone' $\mathrm{x}$ 'Fundacep Raízes' possibilita ganhos para os caracteres de rendimento e alia maior precocidade.

5. Pela capacidade específica de combinação, verifica-se que esforços no intercruzamento entre os genitores 'BRS Guamirim', 'BRS Timbaúva', 'Fundacep Cristalino', 'Fundacep Raízes' e 'Abalone' 
são suficientes para a obtenção de progresso para o conjunto de caracteres estudados.

\section{Agradecimentos}

Ao Conselho Nacional de Desenvolvimento Científico e Tecnológico e à Fundação Araucária, pelo apoio financeiro.

\section{Referências}

ANTUNES, I.F.; VELLO, N.A.; TEIXEIRA, M.G.; SILVEIRA, E.P.; EMYGDIO, B.M.; ZONTA, E.P. Predição da produtividade de grãos de populações F2 de feijão a partir da média parental. Ciência Rural, v.28, p.357-360, 1998.

BENIN, G.; CARVALHO, F.I.F. de; OLIVEIRA, A.C. de; MARCHIORO, V.S.; VIEIRA, E.A.; BERTAN, I.; VALÉRIO, I.P.; MARCHESE, J.A.; MATEI, G. Morphological and AFLP markers for describing genetic relationships among white-oat genotypes. Bragantia, v.67, p.563-568, 2008.

BERTAN, I.; CARVALHO, F.I.F. de; OLIVEIRA, A.C. de; BENIN, G.; VIEIRA, E.A.; VALÉRIO, I.P. Morphological, pedigree, and molecular distances and their association with hybrid wheat performance. Pesquisa Agropecuária Brasileira, v.44, p.155-163, 2009.

CRUZ, C.D. Programa Genes: análise multivariada e simulação. Viçosa: UFV, 2006. v.1, 175p.

CRUZ, C.D.; REGAZZI, A.J. Modelos biométricos aplicados ao melhoramento genético. 2.ed. Viçosa: UFV, 1997. 390p.

GANDIN, C.L. Análise dos efeitos de populações segregantes e da capacidade combinatória de diferentes genótipos sobre os principais caracteres de importância em trigo. 1982. 135p. Dissertação (Mestrado) - Universidade Federal do Rio Grande do Sul, Porto Alegre.

GRIFFING, B. Concept of general and specific combining ability in relation to diallel crossing systems. Australian Journal of Biological Sciences, v.9, p.463-493, 1956.

HARRIS, R.J. A primer of multivariate statistics. New York: Academic, 1975. 332p.

JUNG, M.S.; VIEIRA, E.A.; SILVA, G.O. da; BRANCKER, A.; NODARI, R.O. Capacidade de combinação por meio de análise multivariada para caracteres fenotípicos em maracujazeiro-doce. Pesquisa Agropecuária Brasileira, v.42, p.689-694, 2007.

LEDO, C.A. da S.; FERREIRA, D.F.; RAMALHO, M.A.P. Análise de variância multivariada para os cruzamentos dialélicos. Ciência e Agrotecnologia, v.27, p.1214-1221, 2003.

LORENCETTI, C.; CARVALHO, F.I.F. de; OLIVEIRA, A.C. de; VALÉRIO, I.P.; VIEIRA, E.A.; SILVA, J.A.G. da; RIBEIRO, G. Estimativa do desempenho de progênies F2 e F3 com base no comportamento dos genitores e dos híbridos F1 em aveia. Bragantia, v.65, p.207-214, 2006.

PAINI, J.N.; CRUZ, C.D.; DELBONI, J.S.; SCAPIM, C.A. Capacidade combinatória e heterose em cruzamentos intervarietais de milho avaliados sob as condições climáticas da região Sul do Brasil. Revista Ceres, v.43, p.288-300, 1996.

PFANN, A.Z.; FARIAI, M.V.; ANDRADE, A.A. de; NASCIMENTO, I.R. do; FARIA, C.M.D.R.; BRINGHENTTI, R.M. Capacidade combinatória entre híbridos simples de milho em dialelo circulante. Ciência Rural, v.39, p.635-641, 2009.

SAKAGUTI, E.S. Utilização de técnicas de análise multivariadas na avaliação de cruzamentos dialélicos em coelhos. 1994. 172p. Dissertação (Mestrado) - Universidade Federal de Viçosa, Viçosa.

SAS INSTITUTE. Getting started with the SAS learning edition. Cary: SAS Institute, 2002. 200p.

SILVA, G.O. da; PEREIRA, A. da S.; SOUZA, V.Q. de; CARVALHO, F.I.F. de; VIEIRA, E.A. Capacidade de combinação multivariada para caracteres de tubérculo em gerações iniciais de seleção em batata. Ciência Rural, v.38, p.321-325, 2008.

VIEIRA, E.A.; CARVALHO, F.I.F. de; BERTAN, I.; KOOP, M.M.; ZIMMER, P.D.; BENIN, G.; SILVA, J.A.G. da; HARTWIG, I.; MALONE, G.; OLIVEIRA, A.C. de. Association between genetic distances in wheat (Triticum aestivum L.) as estimated by AFLP and morphological markers. Genetics and Molecular Biology, v.30, p.392-399, 2007.

YAN, W.K.; HUNT, L.A. Biplot analysis of diallel data. Crop Science, v.42, p.21-30, 2002.

Recebido em 5 de maio de 2009 e aprovado em 2 de agosto de 2009 